Revista Brasileira de Agricultura Irrigada v.7, nº 4, p. 258 - 268, 2013

ISSN 1982-7679 (On-line)

Fortaleza, CE, INOVAGRI - http://www.inovagri.org.br

DOI: $10.7127 /$ rbai.v7n400018

Protocolo 018.13 - 07/05/2013 Aprovado em 12/08/2013

\title{
BALANÇO HÍDRICO CLIMATOLÓGICO E CLASSIFICAÇÃo CLIMÁTICA PARA A ÁREA PRODUTORA DA BANANA DO MUNICÍPIO DE BARBALHA, CE.
}

\author{
Raimundo Mainar de Medeiros ${ }^{1}$, João Alvino Sampaio da Silva ${ }^{2}$, Aline de Oliveira Silva ${ }^{3}$, \\ Rigoberto Moreira de Matos ${ }^{4}$, Daiane Pereira Balbino ${ }^{5}$
}

\begin{abstract}
RESUMO
Utilizou-se das variações dos elementos e fatores climáticos, o balanço hídrico desenvolvido por Thornthwaite e Mather e a classificação climática segundo Thornthwaite e pelo método Köppen para demonstrar que o município de Barbalha, Ceará, tem aptidão total para o cultivo da bananeira. $\mathrm{O}$ vento pode ser um dos fatores limitantes para a exploração comercial da bananicultura, se as cultivares forem de porte alto e plantado em solos arenosos. Em locais com elevada insolação, o período para que o cacho atinja o ponto de corte oscila entre 80 e 90 dias. Sob pouca insolação, o período para que o cacho atinja o ponto de corte comercial pode variar entre 85 e 112 dias após a sua emissão.
\end{abstract}

Palavras-chave: Implantação, Fatores e Elementos Climáticos.

\section{CLIMATIC WATER BALANCE AND CLIMATIC CLASSIFICATION FOR THE BANANA PRODUCING AREA OF THE CITY OF BARBALHA, CE}

\begin{abstract}
Was used variations of elements and climatic factors, water balance developed by Thornthwaite and Mather and climatic classification according to Thornthwaite and Köppen method to demonstrate that the City of Barbalha, Ceará, Brazil, has fitness total for the cultivation of banana. The wind can be a limiting factor for the banana crop, the cultivars are tall and planted in sandy soils. In places with high insolation, the period for which the cluster reaches cutoff ranges between 80 and 90 days. After its issuance, under low insolation, the period for the bunch reaches the point of commercial logging can vary between 85 and 112 days.

Keywords: Deployment, Factors and Climatic Elements.

\footnotetext{
${ }^{1}$ Doutorando em Meteorologia, E-mail: mainarmedeiros@gmail.com;

${ }^{2}$ Mestre em Meteorologia, E-mail: alvinosampaio@yahoo.com.br;

${ }^{3}$ Mestre em Engenharia Agrícola, E-mail: alineagroindustria@gmail.com;

${ }^{4}$ Graduando em Irrigação e Drenagem, E-mail: rigobertomoreira@ @mail.com;

${ }^{5}$ Graduando em Irrigação e Drenagem, E-mail: daianebalbino_@ hotmail.com.

1,2,3 Universidade Federal de Campina Grande, Av. Aprígio Veloso, 882 - Bairro Universitário, 58.109-970 Campina Grande, Paraíba, Brasil.

${ }^{4,5}$ Instituto Centro de Ensino Tecnológico CENTEC FATEC - Cariri, Rua Professora Francismar Roque, s/nº Bairro Triângulo, 63.050-530 - Juazeiro do Norte, Ceará, Brasil.
} 


\section{BALANÇO HÍDRICO CLIMATOLÓGICO E CLASSIFICAÇÃO CLIMÁTICA PARA A ÁREA PRODUTORA DA BANANA DO MUNICÍPIO DE BARBALHA, CE}

\section{INTRODUÇÃO}

A banana (Musa sapientum) é uma das frutas tropicais mais exploradas mundialmente. Devido ao seu custo relativamente baixo e ao alto valor nutritivo é parte integrante na alimentação, principalmente, das populações de baixa renda. O Brasil está entre os maiores produtores de banana do mundo, ocupando a terceira posição, com uma produção aproximada de 6,3 milhões de toneladas $\mathrm{ano}^{-1}$, em 2002, ocupando uma área de 508 mil hectares (FAO, 2006).

A bananeira é uma planta tipicamente tropical, exigente em temperaturas elevadas, precipitação bem distribuída e disponibilidade de umidade no solo.

A temperatura ótima para o desenvolvimento das bananeiras oscila em torno de $28,0^{\circ} \mathrm{C}$, enquanto temperaturas de $15,0^{\circ} \mathrm{C}$ e $35,0^{\circ} \mathrm{C}$ são os limites extremos para exploração da cultura. Dessa forma, se uma região apresenta valores de temperatura dentro desses limites e adequado suprimento de água e nutrientes, é possível o cultivo da bananeira nessa área.

Na cultura da bananeira, um manejo de irrigação inadequado pode prejudicar o crescimento e o desenvolvimento das plantas, diminuindo a produtividade. Sob severa deficiência hídrica, a roseta foliar da bananeira se comprime, dificultando ou até mesmo impedindo o lançamento da inflorescência. Consequentemente, o cacho pode não apresentar valor comercial (MOREIRA, 1997).

Em função de sua morfologia e da hidratação de seus tecidos, a bananeira apresenta um elevado consumo de água. As maiores produções estão associadas a uma precipitação total anual de $1.900 \mathrm{~mm}$, bem distribuídas no decorrer do ano (ALVES, 1997). Em grande parte das regiões onde a bananeira é cultivada, as precipitações são insuficientes para atenderem às necessidades hídricas, tornando-se necessário o uso de irrigação suplementar, como ocorre no semiárido nordestino.

A evapotranspiração (ET) é o parâmetro mais importante para se determinar às necessidades hídricas da planta, pois as mesmas dependem fundamentalmente das condições microclimáticas, tais como precipitação, velocidade do vento, temperatura, umidade relativa e radiação solar; das características das plantas, entre elas, cultivar, estágio vegetativo, índice de área foliar, extensão e profundidade das raízes e atividade metabólica da planta; e ainda da água disponível no solo (FERREIRA, 1988).

Das diversas fruteiras tropicais irrigadas, a bananeira é uma planta muito sensível ao estresse hídrico, também possui elevado índice de área foliar, o que resulta em alta transpiração; o sistema radicular é muito superficial, razão pela qual a bananeira é uma espécie que apresenta considerável resposta fisiológica à escassez de água (VOSSELEN et al., 2005); além do mais, demandam água ao longo de todo o ano por se tratar de cultivo perene com produção constante.

Para definir a aptidão da região para o cultivo da bananeira, o produtor deve ter conhecimento das características climatológicas e as suas variações sazonais, uma vez que a bananeira não tolera encharcamento, ventos fortes $\mathrm{e}$ temperaturas médias abaixo de $15^{\circ} \mathrm{C}$ (VENTURA; GOMES, 2005). O objetivo desse trabalho é apresentar os elementos climáticos, o balanço hídrico desenvolvido por Thornthwaite e Mather (1955) e a classificação climática segundo Thornthwaite e pelo método Köppen para Barbalha, CE, demonstrando que o município tem aptidão total para o cultivo da bananeira. 


\section{BALANÇO HÍDRICO CLIMATOLÓGICO E CLASSIFICAÇÃO CLIMÁTICA PARA A ÁREA PRODUTORA DA BANANA DO MUNICÍPIO DE BARBALHA, CE}

\section{MATERIAL E MÉTODOS}

O município de Barbalha, localizado no estado do Ceará, possui uma área de $479.184 \mathrm{~km}^{2}$. Seu posicionamento encontra-se entre os paralelos $7^{\circ} 19^{\prime} 18^{\prime \prime}$ de latitude sul e entre os meridianos de $39^{\circ} 18^{\prime} 07^{\prime \prime}$ de longitude oeste. Inserido na mesorregião Sul Cearense, na microrregião do Cariri, limita-se com os municípios de Crato, Juazeiro do Norte, Missão Velha (Figura 1). Conta com uma população de 55.373 habitantes segundo o IBGE (2010), e uma densidade demográfica de 115,56 habitantes por $\mathrm{km}^{2}$ (IPECE, 2006).

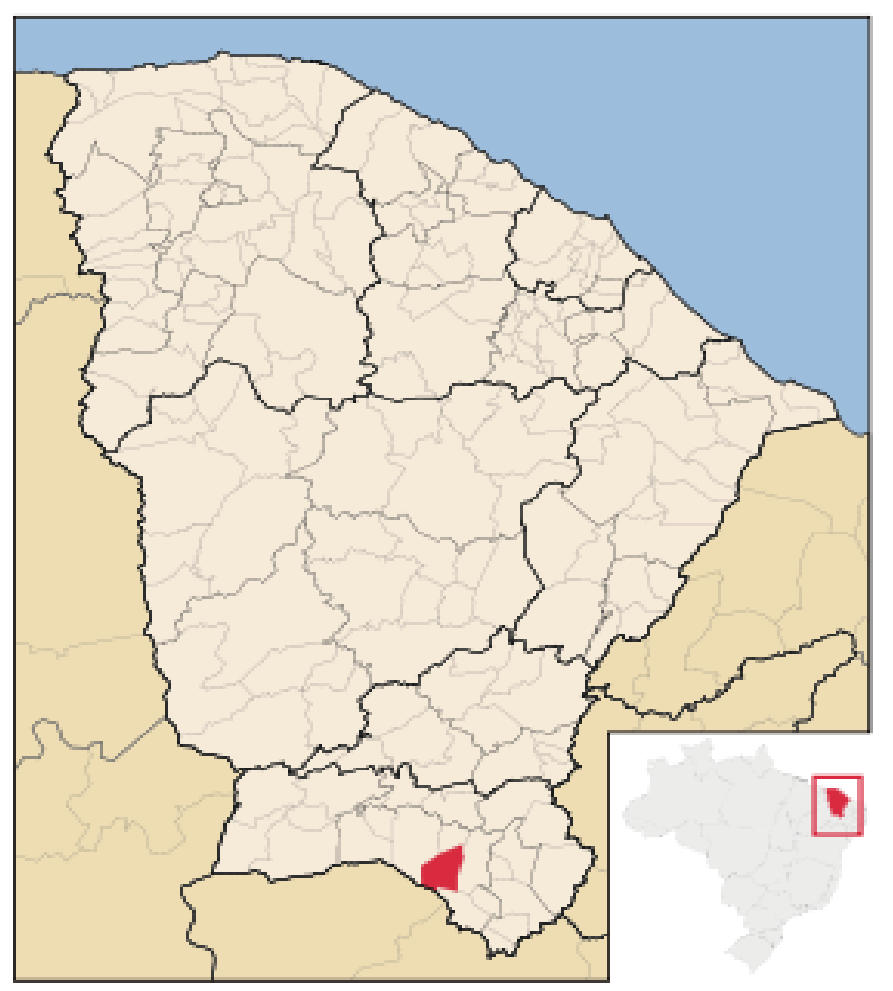

Figura 1. Mapa de localização da área de estudo

Barbalha caracteriza-se como cidade de relevo bastante heterogêneo, repleta de acidentes geográficos, próxima a um divisor de águas natural que é a Chapada do Araripe, o que justifica a média pluviométrica de $1.160,1 \mathrm{~mm}$ (SOARES; RIBEIRO, 2006).

O município está inserido na bacia hidrográfica do Rio Salgado (Figura 2) e possui dois tipos principais de solo: latossolo e sedimentar, onde a principal elevação é a serra do Araripe. A bacia sedimentar tem como característica a formação de aquíferos onde existem várias fontes de água (SOUZA, 1988). A vegetação é bastante diversificada, apresentando domínios de cerradão, caatinga e cerrado. Dentro de sua área encontra-se a Floresta Nacional do Araripe. (SOUZA, 1988; COSTA et al., 2004; BRANDÃO et al., 2012). 


\section{BALANÇO HÍDRICO CLIMATOLÓGICO E CLASSIFICAÇÃO CLIMÁTICA PARA A ÁREA PRODUTORA DA BANANA DO MUNICÍPIO DE BARBALHA, CE}

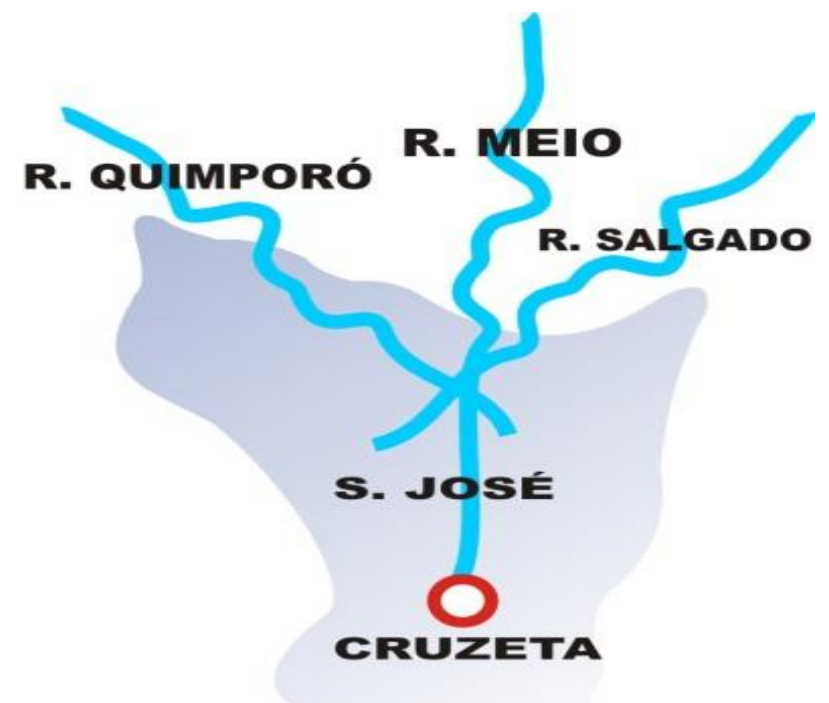

Figura 2. Mapa da Bacia Hidrográfica do rio Salgado.

A maior parte do sistema radicular da bananeira concentra-se nos primeiros 40 $\mathrm{cm}$ de profundidade do solo. A prática da subsolagem deve ser realizada sempre que for feito o cultivo da bananeira pela primeira vez e por ocasião da reforma do plantio velho. A bananeira exige solos bem arejados, portanto, a drenagem é necessária para os solos que apresentem tendência ao alagamento ou encharcamento.

Os dados de temperatura máxima, mínima, média e amplitude térmica; umidade relativa do ar; velocidade e direção predominante do vento; evaporação e evapotranspiração; insolação total, cobertura de nuvens, precipitação e pressão atmosférica foram adquiridas das normais climatológicas do Brasil (INMET, 1990).

Foi adotado o valor de $100 \mathrm{~mm}$ para a capacidade de água disponível no solo (CAD), levando em consideração o plantio de culturas perenes na região. Realizou-se o balanço hídrico climatológico, considerando as médias mensais de temperatura e precipitação pelo método de Thornthwaite e Mather (1955). Foram construídos gráficos resultantes dos valores obtidos na contabilidade hídrica para o período estabelecido.
A classificação climática foi feita segundo o método proposto por Thornthwaite e o método proposto por Köppen, descritos em Vianello e Alves (1991). O tipo climático da região pelo método de Thornthwaite foi determinado com base nos valores dos índices hídrico (Ih), de aridez (Ia), de umidade (Iu) e de eficiência térmica (TE), que são em função da evapotranspiração potencial, da deficiência e do excedente hídrico resultantes dos cálculos da contabilidade hídrica. A classificação proposta por Köppen leva em consideração os dados médios de temperatura do ar e precipitação da região e associa a uma simbologia que representa os tipos e variedades climáticas.

O balanço hídrico foi calculado a partir do modelo matemático proposto por Thornthwaite e Mather (1955). Tomou-se o valor de capacidade de água disponível no solo (CAD) de $100 \mathrm{~mm}$; e como valor de referência para deficiência hídrica (DA) adotou-se o valor de $100 \mathrm{~mm}$. Portanto, deficiência hídrica anual de DA $=100 \mathrm{~mm}$, considerado o limite, acima do qual a faixa se torna restrita a inapta para a cultura da banana. 


\section{BALANÇO HÍDRICO CLIMATOLÓGICO E CLASSIFICAÇÃO CLIMÁTICA PARA A ÁREA PRODUTORA DA BANANA DO MUNICÍPIO DE BARBALHA, CE}

\section{RESULTADOS E DISCUSSÕES}

As analises relacionadas abaixo dos elementos meteorológicos nos demonstram as variabilidades ocorridas entre os anos de 1961-1990 para o município de Barbalha, como contribuição do estudo da cultura da banana suas condições propícias ao cultivo.

Barbalha apresenta uma altitude média de 409,0 m, considerada satisfatória para o cultivo da bananeira, que deve ser cultivada em locais que variam de $0 \mathrm{a}$
$1.000 \mathrm{~m}$ acima do nível do mar. As oscilações na altitude alteram a duração do ciclo da bananeira, evidenciando-se que há um aumento de 30 a 45 dias no ciclo de produção desta cultura para cada $100 \mathrm{~m}$ de acréscimo na altitude.

Na Tabela 1 são apresentados os valores médios climatológicos dos elementos meteorológicos estudados para o município de Barbalha, referente ao período de 1961-1990.

Tabela 1. Normais Climatológicas (Período 1961 a 1990). Barbalha, 2009.

\begin{tabular}{|c|c|c|c|c|c|c|c|c|c|c|c|c|c|}
\hline $\begin{array}{l}\text { PARÂMETROS } \\
\text { /MESES }\end{array}$ & JAN & FEV & MAR & ABR & MAI & JUN & JUL & $\mathrm{AGO}$ & SET & OUT & NOV & DEZ & ANUAL \\
\hline $\begin{array}{l}\text { TEMPERATURA } \\
\text { MÁXIMA }\end{array}$ & 32,1 & 30,9 & 30,3 & 30,1 & 30,0 & 29,7 & 29,9 & 31,7 & 33,3 & 34,1 & 33,9 & 33,1 & 31,6 \\
\hline $\begin{array}{l}\text { TEMPERATURA } \\
\text { MÍNIMA }\end{array}$ & 21,2 & 21,1 & 20,9 & 20,5 & 19,8 & 19,3 & 19,1 & 18,8 & 20,1 & 21,1 & 21,8 & 21,7 & 20,5 \\
\hline $\begin{array}{l}\text { TEMPERATURA } \\
\text { MÉDIA }\end{array}$ & 25,3 & 24,6 & 24,2 & 24,0 & 23,9 & 23,7 & 23,7 & 24,6 & 26,0 & 26,4 & 26,5 & 26,2 & 24,9 \\
\hline $\begin{array}{l}\text { AMPLITUDE } \\
\text { TÉRMICA }\end{array}$ & 10,9 & 9,8 & 9,4 & 9,6 & 10,2 & 10,4 & 10,8 & 12,9 & 13,2 & 13,0 & 12,1 & 11,4 & 11,1 \\
\hline $\begin{array}{l}\text { UMIDADE } \\
\text { RELATIVA }\end{array}$ & 68,0 & 74,0 & 80,0 & 79,0 & 73,0 & 67,0 & 61,0 & 53,0 & 49,0 & 51,0 & 53,0 & 55,0 & 63,6 \\
\hline $\begin{array}{l}\text { VELOCIDADE } \\
\text { VENTO }\end{array}$ & 1,41 & 1,39 & 1,32 & 1,48 & 1,72 & 2,18 & 2,55 & 2,52 & 2,54 & 2,02 & 1,85 & 1,77 & 1,90 \\
\hline $\begin{array}{l}\text { DIREÇÃO } \\
\text { VENTO }\end{array}$ & Indef. & Indef. & $\mathrm{E}$ & $\mathrm{E}$ & SE & SE & SE & SE & SE & $\mathrm{E}$ & $\mathrm{NE}$ & $\mathrm{NE}$ & SE \\
\hline EVAPORAÇÃO & 151,6 & 107,7 & 93,7 & 96,1 & 135,5 & 170,4 & 208,1 & 256,5 & 274,4 & 254,7 & 235,0 & 208,7 & 2192,4 \\
\hline $\begin{array}{l}\text { EVAPOTRANSPI } \\
\text { RAÇÃO }\end{array}$ & 106,1 & 75,4 & 65,6 & 67,3 & 94,9 & 119,3 & 145,7 & 179,6 & 192,1 & 178,3 & 164,5 & 146,1 & 1534,7 \\
\hline INSOLAÇÃO & 216,4 & 191,9 & 198,4 & 206,1 & 224,9 & 240,0 & 252,4 & 281,8 & 276,4 & 268,9 & 256,4 & 234,4 & 2848,0 \\
\hline NEBULOSIDADE & 0,7 & 0,7 & 0,6 & 0,6 & 0,8 & 0,5 & 0,7 & 0,3 & 0,4 & 0,5 & 0,5 & 0,6 & 0,6 \\
\hline PRECIPITAÇÃO & 171,4 & 226,5 & 227,1 & 208,3 & 42,8 & 20,6 & 14,7 & 5,8 & 9,3 & 20,7 & 42,2 & 86,4 & 1075,8 \\
\hline $\begin{array}{c}\text { PRESSÃO } \\
\text { ATMOSFÉRICA }\end{array}$ & 963,8 & 964,3 & 964,4 & 964,9 & 965,9 & 967,4 & 968,4 & 967,3 & 966,2 & 964,7 & 963,8 & 963,8 & 965,4 \\
\hline
\end{tabular}

FONTE: INMET (2009)

A cultura da banana tem faixas de temperaturas que contribuem para seu desenvolvimento conforme descrito abaixo:

a) Temperatura média anual $(\mathrm{Ta})=15.0^{\circ} \mathrm{C}$ indica o limite inferior da faixa térmica apta à produção da banana. Abaixo desse limite a cultura sofre deficiência térmica, que provoca uma queda na produção, tornando-se a área restrita a inapta, para a cultura comercial. b) Temperatura média anual (Ta) entre $15.0^{\circ} \mathrm{C}$ e $35^{\circ} \mathrm{C}$ indica a faixa térmica favorável à cultura da banana.

c) Temperatura média anual (Ta) maior que $35^{\circ} \mathrm{C}$ indica o limite superior da faixa térmica favorável à cultura da banana. Acima desse limite, a faixa é considerada restrita a inapta, decorrente, principalmente, das reduções provocadas na produtividade pelas elevadas temperaturas. 


\section{BALANÇO HÍDRICO CLIMATOLÓGICO E CLASSIFICAÇÃO CLIMÁTICA PARA A ÁREA PRODUTORA DA BANANA DO MUNICÍPIO DE BARBALHA, CE}

A temperatura máxima media anual é de $31,6^{\circ} \mathrm{C}$ e suas flutuações mensais oscilam entre $34,1^{\circ} \mathrm{C}$ no mês de outubro a $29,7^{\circ} \mathrm{C}$ no mês de junho. A temperatura média anual é de $24,9^{\circ} \mathrm{C}$, com a maior média ocorrendo no mês de novembro $\left(26,5^{\circ} \mathrm{C}\right)$, caracterizando um mês típico de verão e a menor média ocorre nos meses de junho e julho $\left(23,7^{\circ} \mathrm{C}\right)$. A variabilidade da temperatura mínima mensal oscila de $18,8^{\circ} \mathrm{C}$ no mês de agosto a $21,8^{\circ} \mathrm{C}$ no mês de novembro sua temperatura anual é $20,5^{\circ} \mathrm{C}$, período em que ocorrem temperaturas amenas na região (Figura 3). Tem uma amplitude térmica de $11,1^{\circ} \mathrm{C}$ e sua variação mensal oscilam entre $9,4^{\circ} \mathrm{C}$ em março a $13,2^{\circ} \mathrm{C}$ em setembro.

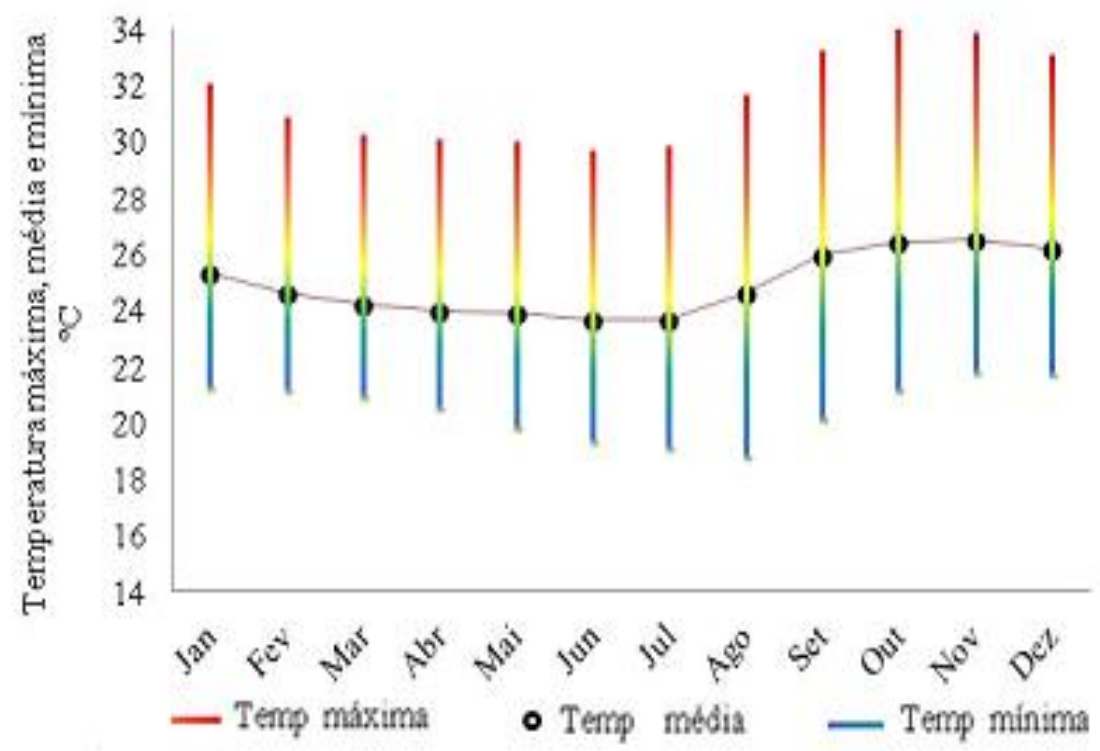

Figura 3. Variação média anual de temperatura máxima, média e mínima do município de Barbalha CE, no período de 1961 - 1990. Fonte: INMET (2009)

A média anual de precipitação é $1.075,8 \mathrm{~mm}$, podendo ser dividido em dois períodos. Um chuvoso, entre os meses de dezembro a maio, com oscilações mensais nos seus índices flutuando entre 42,8 a $227,1 \mathrm{~mm}$, com um total de $962,5 \mathrm{~mm}$, que corresponde a $89,46 \%$ do total acumulado e um período menos chuvoso entre os meses de junho a novembro, com um total de $113,3 \mathrm{~mm}$ que corresponde a 10,53\% do total (Figura 4). A umidade relativa do ar segue em consonância com a precipitação, apresenta uma variação anual de 63,6\% e $80 \%$ no mês de março (maior valor) sendo $49 \%$ seu menor valor registrado de umidade relativa, no mês de setembro.
Para atender às necessidades hídricas, especialmente da bananeira, que necessita de, pelo menos, $1200 \mathrm{~mm}$ anuais ou, em média, $100 \mathrm{~mm}$ por mês. No município de Barbalha faz-se necessário o uso de irrigações durante os meses de maio a dezembro, visto que nestes meses ocorre déficit hídrico.

A umidade relativa média da área estudada é inferior às médias anuais mais adequadas para a bananeira, que apresenta melhor desenvolvimento em locais com médias anuais de umidade relativa superiores a $80 \%$. Esse limite é decorrente da origem da espécie, de regiões tropicais úmidas. 


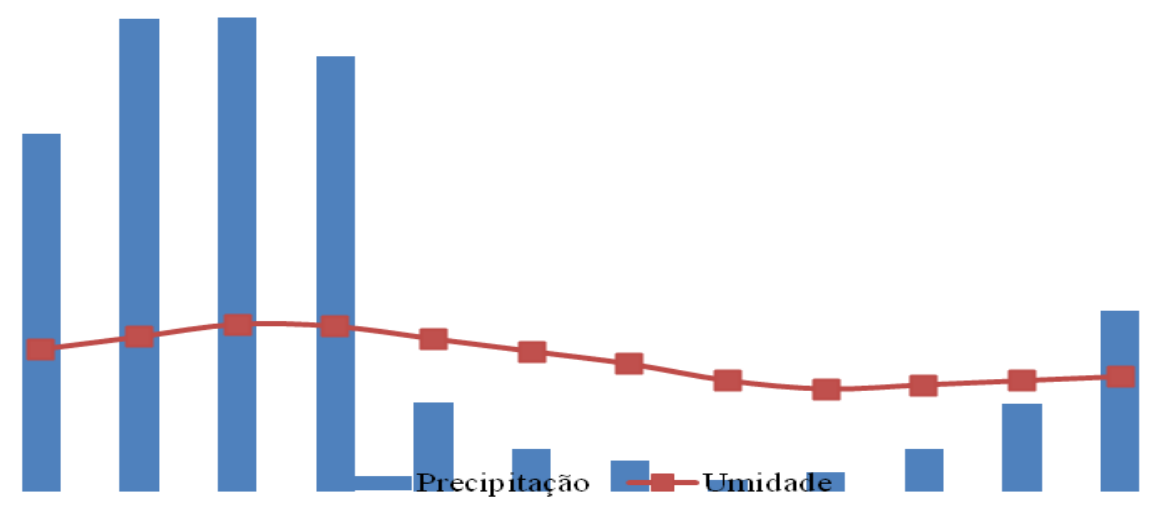

Figura 4. Variação média anual de precipitação e da umidade relativa do ar no município de Barbalha - CE, no período de 1961 - 1990. Fonte: INMET (2009)

O vento é outro elemento climático importante, podendo causar, desde pequenos danos, até a destruição do bananal. Velocidade de vento inferior a $8,33 \mathrm{~m} \mathrm{~s}^{-1}$, geralmente, não prejudica a planta, ou seja, não é limitante para o cultivo da banana.

Conforme a Figura 5 a variação média anual da velocidade do vento é de $1,90 \mathrm{~m} \mathrm{~s}^{-1}$, nos meses de junho a outubro a intensidade do vento flui entre 2,02 a 2,55 $\mathrm{m} \mathrm{s}^{-1}$. E nos meses de novembro a maio a flutuação de sua intensidade é de 1,32 a $1,85 \mathrm{~m} \mathrm{~s}^{-1}$. No que se refere à velocidade do vento, mais importante do que a média diária ou mensal, é seu valor instantâneo ao longo do dia, pois uma rajada de vento ou um vendaval que ocorre em alguns minutos é capaz de provocar destruição do bananal. Salienta-se que nestes valores não estão contabilizadas as rajadas de vento que ocorrem nesta área.

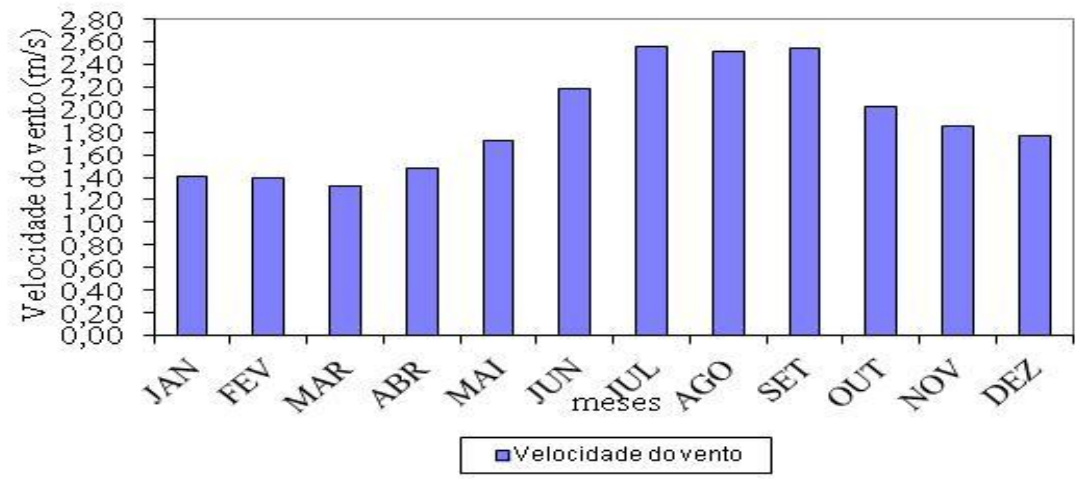

Figura 5. Variação média anual da velocidade do vento no município de Barbalha - CE, no período de 1961 - 1990. Fonte: INMET (2009)

$\mathrm{Na}$ Figura 6 observam-se as flutuações da evaporação e evapotranspiração referente ao período de 1961 - 1990 para o município de Barbalha. A evaporação anual é de 2.192,4 mm e suas maiores flutuações ocorrem entre os meses de julho a dezembro com oscilação de 208,1 a $274,4 \mathrm{~mm}$, os menores valores evaporados ocorrem nos meses de janeiro a junho com flutuação entre 93,7 a $170,4 \mathrm{~mm}$. Apresenta um valor anual evapotranspirado de $1.534,7 \mathrm{~mm}$ e suas maiores flutuações ocorrem entre os meses de junho a janeiro (106,1 a 192,2 $\mathrm{mm})$ e nos meses de fevereiro a maio os índices evapotranspirados oscilam de 65,6 a $94,9 \mathrm{~mm}$. 


\section{BALANÇO HÍDRICO CLIMATOLÓGICO E CLASSIFICAÇÃO CLIMÁTICA PARA A ÁREA PRODUTORA DA BANANA DO MUNICÍPIO DE BARBALHA, CE}

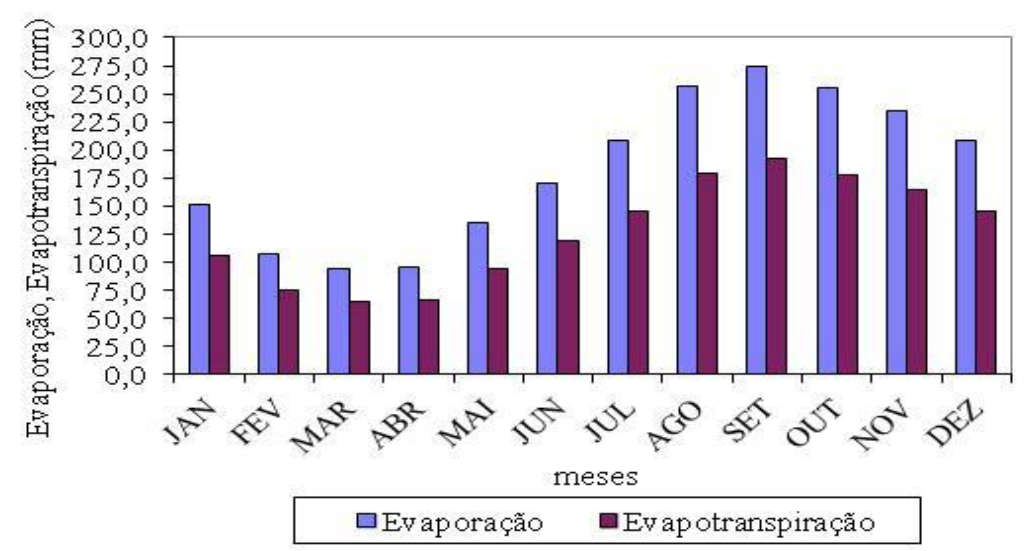

Figura 6. Variação média da evaporação e evapotranspiração do município de Barbalha - CE, no período de 1961 - 1990. Fonte: INMET (2009)

As altas taxas de horas de insolação total correm quase que o ano todo (abril a janeiro), e os meses de fevereiro e março com os menores índices (Figura 7), apresenta uma taxa anual de $2.848,0$ horas de brilho solar. Os menores índices de cobertura de nebulosidade ocorrem nos meses de agosto e setembro com 0,3 e 0,4 décimos respectivamente, a sua taxa anual é 0,6 décimos.

O efeito da luminosidade sobre o ciclo vegetativo da bananeira é evidenciado em algumas publicações com plantio adensado, por exemplo. Em locais com elevada insolação, o período para que o cacho atinja ponto de corte oscila entre 80 e 90 dias. Após sua emissão, sob pouca insolação, o período para que o cacho atinja o ponto de corte comercial pode variar entre 85 e 112 dias. Por outro lado, verifica-se um aumento da atividade fotossintética quando na faixa luminosa entre 2.000 e 10.000 lux, sendo mais lenta na faixa de 10.000 a 30.000 lux. Valores inferiores a 1.000 lux são insuficientes para o desenvolvimento da planta, e valores elevados podem acarretarqueima das folhas, principalmente quando estas estão na fase de cartucho.

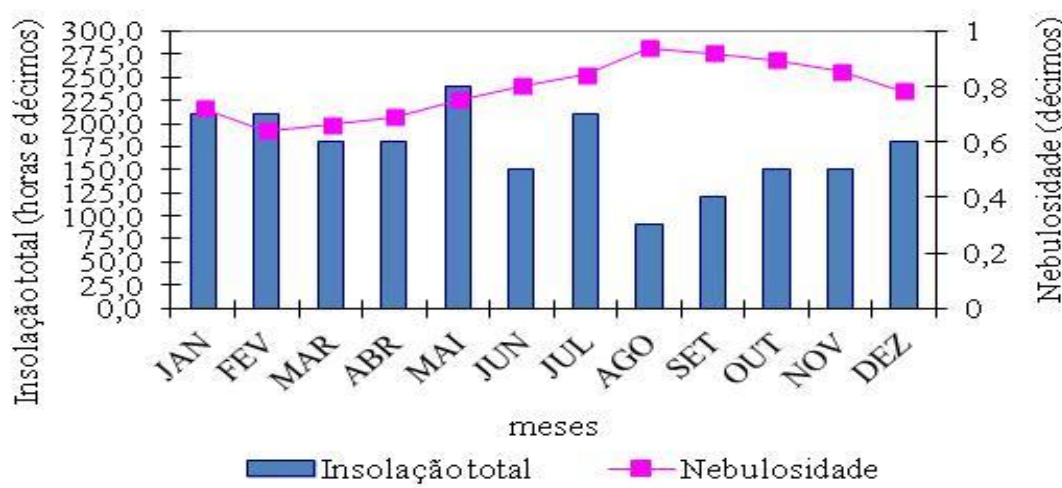

Figura 7. Variação média anual da insolação e nebulosidade no município de Barbalha - CE, no período de 1961 - 1990. Fonte: INMET (2009) 


\section{BALANÇO HÍDRICO CLIMATOLÓGICO E CLASSIFICAÇÃO CLIMÁTICA PARA A ÁREA PRODUTORA DA BANANA DO MUNICÍPIO DE BARBALHA, CE}

Na Tabela 2 é apresentado um

cultura da bananeira. quadro resumo da aptidão climática da

Tabela 2. Síntese da aptidão climática da cultura da bananeira

\begin{tabular}{|c|c|c|c|}
\hline CULTURA & APTIDÃO & ÍNDICE CLIMÁTICO & DEFICIÊNCIA/EXCESSO \\
\hline \multirow[t]{4}{*}{ BANANA } & Plena & $\rightarrow \mathrm{D}<200 \mathrm{~m}$ & $\begin{array}{l}\Rightarrow \text { Boas condições hídricas para o } \\
\text { desenvolvimento da cultura. }\end{array}$ \\
\hline & Moderada & $\rightarrow 200<\mathrm{D}<350 \mathrm{~m}$ & $\begin{array}{l}\Rightarrow \text { Insuficiência hídrica estacional, } \\
\text { prolongando o ciclo da cultura. }\end{array}$ \\
\hline & Restrita & $\rightarrow 350<\mathrm{D}<700 \mathrm{~m}$ & $\begin{array}{l}\Rightarrow \text { Deficiência hídrica acentuada, } \\
\text { sendo possível o cultivo apenas em } \\
\text { várzeas e locais mais úmidos. }\end{array}$ \\
\hline & Inaptidão & $\rightarrow \mathrm{D}>700 \mathrm{~m}$ & $\begin{array}{l}\Rightarrow \text { Deficiência hídrica muito severa. O } \\
\text { cultivo somente é possível através de } \\
\text { irrigação. }\end{array}$ \\
\hline
\end{tabular}

A Tabela 3 apresenta o Balanço Hídrico Climatológico para o Município de
Barbalha segundo o método proposto por Thornthwaite e Mather (1955).

Tabela 3. Balanço Hídrico Climatológico do Município de Barbalha, segundo Thornthwaite e Mather (1955) (CAD = $100 \mathrm{~mm})$. Latitude 7¹9'18' S, longitude de 39 18'07' W e altitude de 409,0 metros. Período 1961-1990.

\begin{tabular}{cccccc}
\hline $\begin{array}{c}\text { Parâmetros/ } \\
\text { Meses }\end{array}$ & $\begin{array}{c}\text { P } \\
\mathrm{mm}\end{array}$ & $\begin{array}{l}\text { ETP } \\
\mathrm{mm}\end{array}$ & $\begin{array}{l}\text { EVR } \\
\mathrm{mm}\end{array}$ & $\begin{array}{c}\mathrm{DEF} \\
\mathrm{mm}\end{array}$ & $\begin{array}{c}\text { EXC } \\
\mathrm{Mm}\end{array}$ \\
\hline Jan & 171,4 & 121,3 & 121,3 & 0,0 & 0,0 \\
Fev & 226,5 & 102,5 & 102,5 & 0,0 & 74,1 \\
Mar & 227,1 & 106,3 & 106,3 & 0,0 & 120,8 \\
Abr & 208,3 & 98,4 & 98,4 & 0,0 & 109,9 \\
Mai & 42,8 & 98,7 & 85,6 & 13,1 & 0,0 \\
Jun & 20,6 & 91,9 & 49,7 & 42,1 & 0,0 \\
Jul & 14,7 & 94,7 & 30,1 & 64,6 & 0,0 \\
Ago & 5,8 & 107,8 & 13,8 & 93,9 & 0,0 \\
Set & 9,3 & 126,7 & 12,4 & 114,2 & 0,0 \\
Out & 20,7 & 139,8 & 21,7 & 118,2 & 0,0 \\
Nov & 42,2 & 139,2 & 42,5 & 96,7 & 0,0 \\
Dez & 86,4 & 140,1 & 86,5 & 53,7 & 0,0 \\
\hline
\end{tabular}

Os resultados da contabilidade hídrica mostrada na Tabela 3, em que existe a ocorrência de excedente hídrico entre os meses de fevereiro a abril. As deficiências hídricas ocorrem entre os meses de maio a dezembro, sendo os meses de setembro e outubro com maiores taxas de deficiência, é recomendável complementar a lâmina de água no solo através do uso de irrigação, principalmente nos meses citados onde há uma maior perda de água do solo. Ocorre reposição de água no solo nos meses de janeiro e fevereiro e a retirada de água no solo ocorre entre os meses de maio aos primeiros dias do mês de setembro (Figura 8). Os índices de umidade, aridez e hídricos são: 22,29\%; $43,62 \%$ e $-21,31 \%$ respectivamente. 


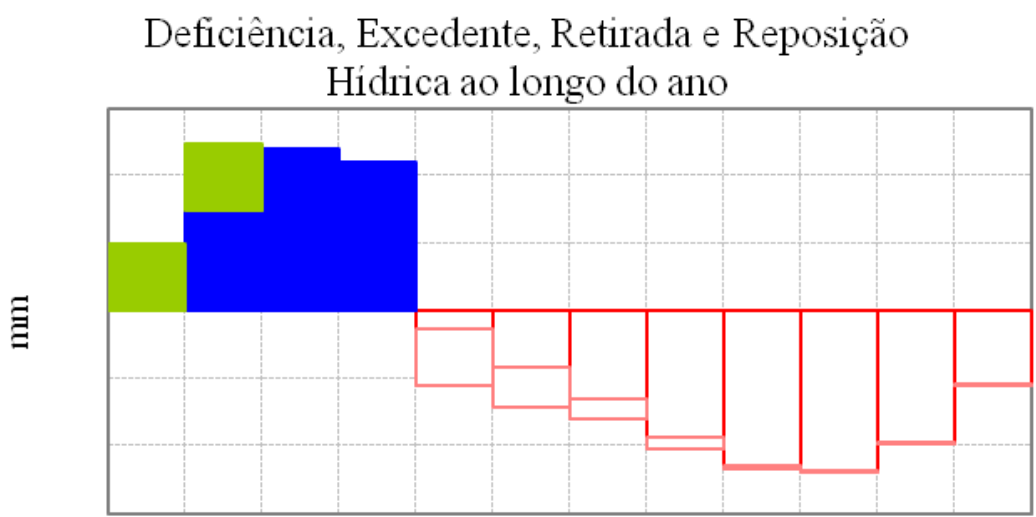

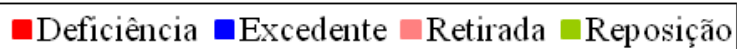

Figura 8. Gráfico do Balanço Hídrico Climatológico do Município de Barbalha segundo Thornthwaite e Mather (1955). Período: 1961-1990.

\section{CONCLUSÕES}

O município de Barbalha torna-se apto para o desenvolvimento da cultura da bananeira por apresentar uma média anual de temperatura superior a $24,9^{\circ} \mathrm{C}$ e ter uma boa disponibilidade hídrica no solo durante o ano. Para manter uma quantidade de água necessária para o desenvolvimento da cultura, é recomendável o uso de irrigação

\section{AGRADECIMENTOS}

A CAPES pela concessão I da bolsa de Doutorado e ao

\section{REFERÊNCIAS BIBLIOGRÁFICAS}

ALVES, E. J. A cultura da banana: aspectos técnicos, socioeconômicos e agroindustriais. Brasília: EMBRAPA-SPI; Cruz das Almas: EMBRAPA CNPMF, 1997. $585 \mathrm{p}$.

BRANDÃO, Z. N.; SOUZA, J. Y. B.; BARBOSA, M. P.; ZONTA, J. H.; BEZERRA, J. R. G. Zoneamento de áreas de plantio e mapeamento de APPS e RLS usando imagens ALOS. IV Simpósio no período onde ocorre déficit hídrico evitando assim a queda da produtividade e o aparecimento de doenças devido ao estresse hídrico.

$O$ vento pode ser um dos fatores limitantes para a exploração comercial da bananicultura, se as cultivares forem de portes altos e plantados em solos arenosos.

Instituto CENTEC pelo apoio.
Brasileiro de Ciências Geodésias e Tecnologias da Geoinformação. Recife, Maio de 2012. Disponível em: www.ufpe.br/cgtg/SIMGEOIV/CD/artigos/ SReFOTO/072_4.pdf Acesso em: $15 \mathrm{de}$ Agosto de 2012.

FAO. STATISTICAL databases. Disponível em: <http:// www.fao.org>. Acesso em: 02 fev. 2006. 


\section{BALANÇO HÍDRICO CLIMATOLÓGICO E CLASSIFICAÇÃO CLIMÁTICA PARA A ÁREA PRODUTORA DA BANANA DO MUNICÍPIO DE BARBALHA, CE}

FERREIRA, E. J. Determinação da evapotranspiração e do coeficiente de cultura (Kc) para a aveia preta (Avena strigosa, Sckereb) irrigada. 1988. $70 \mathrm{f}$. Dissertação (Mestrado em Agronomia) Universidade Federal de Viçosa, Viçosa MG, 1988.

IBGE. Censo 2010. Disponível em: http://www.ibge.gov.br/cidadesat/topwindo w.htm?1> Acesso em 19/11/2011.

INMET. Normais climatológicas do Brasil. 1990.

IPECE. Perfil básico municipal da cidade de Barbalha. Fortaleza, 2006.

MOREIRA, R. S. Banana: teoria e prática de cultivo. Campinas: Fundação Cargill, 1997. 335 p.

SOARES, R. C.; RIBEIRO, S. C. Feições erosivas e movimentos gravitacionais de massa nas áreas urbanas e periurbanas de Barbalha/CE com vistas ao planejamento urbano-ambiental: subsídios para a carta de cadastro. Anais do VI Simpósio Nacional de Geomorfologia, Goiânia, Setembro de $2006 . \quad$ Disponível em: www.labogef.iesa.ufg.br/links/sinageo/arti cles/345.pdf. Acesso em: 12 de Julho de 2012.

THORNTHWAITE, C.W. An approach toward a rational classification of climate. Geogr. Rev, v.38, p.55-94, 1948.

THORNTHWAITE, C.W.; MATHER, J.R. The water balance. Publications in Climatology. New Jersey: Drexel Institute of Technology, 104p. 1955.

VENTURA, J. A.; GOMES, J. A.: Recomendações técnicas para o cultivo de bananeira no Estado do Espírito Santo. Vitória - ES. Incaper, 2005. 42p.

VIANELlO, R. L; ALVES, A. R. Meteorologia básica e Aplicações. Viçosa - MG. Imprensa Universitária, 1991. 449p.

VOSSELEN, V. A.; VERPLANCKE, H.; RANST, V. E. Assessing water consumption of banana: Traditional versus modeling approach. Agricultural Water Management, v.74, p.201-218, 2005. 